\section{POSTMENOPAUSAL FEMALE SMOKERS MORE LIKELY TO LOSE TEETH}

Researchers in Buffalo have shown that postmenopausal women who have smoked are at much higher risk of losing their teeth than women who never smoked.

A study of 1,106 women examined comprehensive smoking histories so that the researchers could unravel some of the causes behind tooth loss in postmenopausal women who smoked. ${ }^{1}$ Smoking has long been associated with tooth loss, but postmenopausal women in particular experience more tooth loss than their male counterparts.

Xiaodan Mai, a doctoral student in epidemiology at the University of Buffalo, said: 'Regardless of having better oral health practices, such as brushing, flossing and visiting the dentist more frequently, postmenopausal women in general

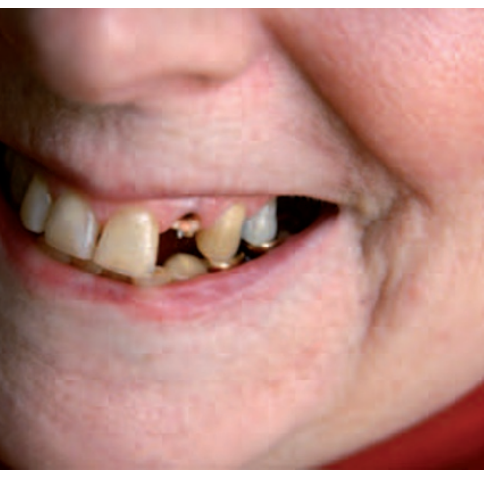

tend to experience more tooth loss than men of the same age.'

In the study, heavy smokers - defined as those who had at least 26 pack-years of smoking, or the equivalent of having smoked a pack a day for 26 years - were nearly twice as likely to report having experienced tooth loss overall and more than six times as likely to have experienced tooth loss due to periodontal disease, compared to those who never smoked.

The study notes that cigarette smoke may accelerate periodontal disease and that other studies suggest that chemicals found in smoke may favour plaque-forming bacteria that could reduce the ability of saliva to be antioxidative. Nicotine also has been shown to reduce bone density and bone mineral factors while oestrogen hormones have been found to be lower among women who smoke.

The researchers also found, however, that smoking was a less important factor in tooth loss due to caries.

1. Mai X, Wactawski-Wende J, Hovey K M et al. Associations between smoking and tooth loss according to the reason for tooth loss: The Buffalo OsteoPerio Study. J Am Dent Assoc 2013; 144: 252-265.

\section{HONOURS, AWARDS, APPOINTMENTS}

Professor John Gibson

Dr John Gibson has been appointed to the Chair of Medicine

in Relation to Dentistry in the University of Glasgow.

Fellowship of the Faculty

Professor David Moles and lan Mills from Plymouth University Peninsula Schools of Medicine and Dentistry have been awarded the prestigious Fellowship of the Faculty of General Dental Practitioners UK. It is unusual for two individuals from the same institution to be awarded Fellowship at the same time.

\section{BDA Superbrand}

The British Dental Association (BDA) has been shortlisted as one of this year's 500 Business Superbrands in the Support Services - Associations \& Accreditations category. Superbrands (UK) Ltd commissions independent research to identify the UK's strongest brands.

\section{Prizewinning name}

Professor Robin Matthews has won a prize for giving a name to the new BUOLD programme at the Bristol Dental School Centenary Meeting. Professor Matthews' winning suggestion was BUOLD 21C - Bristol University Open Learning for Dentists twenty-first century version. www. bris.ac.uk/dentalpg/buold

Top grade clinics

More than 300 dental clinics in the UK have made the top grade on WhatClinic.com, a site for consumers to find and compare private clinics, based on independent feedback and information from millions of users. The website lists more than 100,000 clinics worldwide, and dental treatment accounts for over $40 \%$ of enquiries made on the site.

\title{
HOW THE WHALE GOT HIS PEG-LIKE TEETH
}

New research into the evolution of cetacean dentition has revealed why, unlike other mammals, dolphins and whales do not have precise occlusion and distinct tooth classes. ${ }^{1}$

Armfield et al. studied fossil records to trace when whales evolved their simple, peg-like teeth, discovering that 48 million years ago, before they had fully adapted to their new aquatic existence, whales still possessed the four usual mammalian tooth classes: incisors, canines, premolars and molars. By studying pig embryos (close relatives of whales) researchers could explore how teeth shaped during development, monitoring gene expression to understand how occlusal patterns formed. Bone morphogenetic protein (Bmp4) and fibroblast growth factor $(F g f 8)$ were found to regulate signalling pathways that define whether a tooth will develop into an incisor or molar respectively. In dolphin embryos, however, researchers noted an overlapping presence of $\mathrm{Bmp4}$, causing teeth in these new areas to form as ectopic, simple-crowned teeth.

As whales evolved from land mammals the developmental changes in dentition are most likely the result of a major shift in diet and food processing during the cetacean evolution, as cetaceans use their teeth to grab and hold prey, but not to chew their

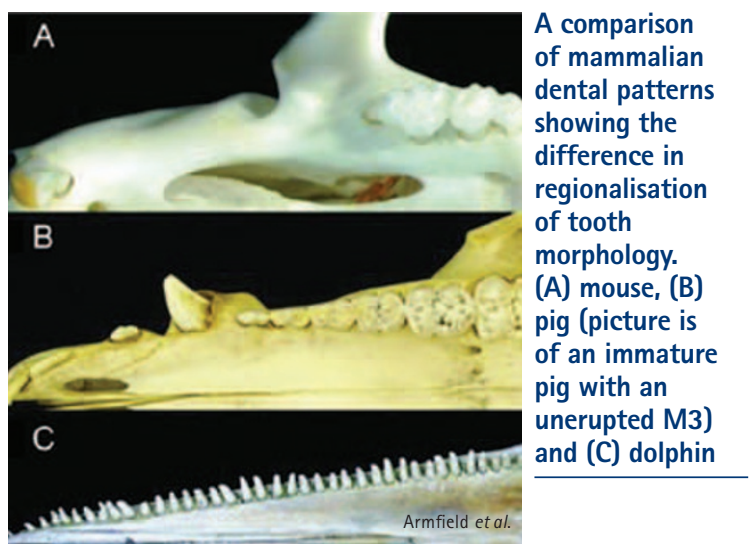

food. As precise occlusion was lost, genetic expression changed, resulting in the modern, simplified dentition that persists today.

1. Armfield B A, Zheng Z, Bajpai S, Vinyard C J, Thewissen J G M. Development and evolution of the unique cetacean dentition. Peer $J$ 2013; 1 : e24.

By Laura Pacey 